\title{
Determination of Mo-Rich Laves-Phase in Weld Metals of a Creep-Resistant 9\% Cr-Steel Using Light Optical Microscopy
}

\author{
H. Pahr ${ }^{1} \cdot$ H. Rojacz ${ }^{2} \cdot$ S. Baumgartner ${ }^{1}$
}

Received: 6 June 2017/Revised: 12 June 2017/ Accepted: 12 June 2017/Published online: 29 June 2017

(C) Springer Science+Business Media, LLC and ASM International 2017

\begin{abstract}
Creep-resistant 9\% Cr-steels feature different phases in their weld metal microstructure; especially after creep-rupture testing. Laves-Phase in such alloying concepts is widely studied, but there is still a need for a simple identification technique utilizing light optical microscopy. The Lichtenegger-Bloech color tint etchant was utilized to contrast the weld metals microstructure in as-welded condition, after post-weld heat treatment and creep-rupture tested. Proof of the presence of Laves-Phase after creeprupture tests in the weld metal of a $9 \% \mathrm{Cr}$-steel GX13CrMoCoVNbNB9-2-1 (CB2) was performed using Lichtenegger-Bloech and light optical microscopy. To validate Laves-Phase within the analyzed microstructure, scanning electron microscopy and energy dispersive $\mathrm{x}$-ray spectroscopy were performed. For a thorough analysis, phase analysis was done in selected regions of interest. The results show that the Laves-Phase in this type of steel can be easily contrasted and quantified at comparatively low lateral resolutions by Lichtenegger-Bloech, with no further need of analysis required.
\end{abstract}

Keywords Metallography $\cdot$ Etching technique $\cdot$ LavesPhase $\cdot$ Light optical microscopy ·

Creep-resistant 9\% Cr-steel

H. Pahr

hannes.pahr@voestalpine.com

1 voestalpine Böhler Welding Austria GmbH, Böhler Welding Straße 1, 8605 Kapfenberg, Austria

2 AC2T Research GmbH, Viktor-Kaplan-Straße 2, 2700 Wiener Neustadt, Austria

\section{Introduction}

Since welding is a key manufacturing process of joining core components in thermal power plants the analysis and characterization of weld microstructures is of great importance. Metallographic preparation followed by light optical microscopy (LOM) of welds is a comparatively simple and economic way of microstructure investigation, which should not be underestimated. It can be efficiently used as a process control, quality control, and failure analysis tool $[1,2]$. Combining thorough metallographic preparation, the correct use of etchants and knowledge of weld microstructures LOM becomes a powerful characterization tool [2]. Many studies which deal with the analysis of weld microstructures rarely use LOM. Mostly, scanning electron microscopy, transmission electron microscopy, electron backscatter diffraction (EBSD), and x-ray diffraction (XRD) is used for phase identification [3-6]. In many cases, when particle sizes are smaller than the lateral resolution capacity of LOM, it does make sense; but for already known phase compositions and routine examinations metallographic investigations can be performed more economically with less complex equipment [1].

For the LOM investigations it is necessary to generate contrast between phases, which can be done by several etching techniques. Basically, contrast is caused by different chemical attack of phases, precipitates, and grain boundaries due to their electrochemical potential and crystal lattice [7, 8]. Selective etching, cathodic and anodic color tint etching, as well as electrochemical etching can be applied to contrast different phases in microstructures [9].

Weld microstructures of creep-resistant $9 \% \mathrm{Cr}$-steels contain a broad spectrum of different present phases, strongly dependent on chemical composition, welding parameters, thermal exposure, and mechanical loads 
[10-12]. In general, a lath martensitic structure occurs as the dominant phase; during post-weld heat treatment (PWHT) carbides and nitrides are precipitated [13].

These fine-dispersed particles, mainly of the type $\mathrm{M}_{23} \mathrm{C}_{6}$ and MX (M-metal, $\mathrm{X}-\mathrm{C}, \mathrm{N})$, are commonly clustered at grain boundaries and subgrains [14]. It should be mentioned that it is difficult to visualize carbides by means of scanning electron microscopy in unetched condition. Usually they cannot be sufficiently visualized on polished samples even within backscatter mode due to the similar density compared to the matrix. Selective etching is required to improve the appearance of carbides in the scanning electron microscopy.

During service or creep-rupture testing (CRT) at elevated temperatures Laves-Phase is formed within the matrix. This $\mathrm{A}_{2} \mathrm{~B}$ intermetallic phase with hexagonal crystal lattice tends to be thermodynamically stable. The most common Laves-Phase formed in this steel is $(\mathrm{Fe}, \mathrm{Cr})_{2}(\mathrm{Mo})[5,15]$. Such phases can stabilize the longterm behavior of $9 \% \mathrm{Cr}$-steels, which enhances creep strength [16]; therefore, the phase determination is of great scientific and practical importance.

The growth of Laves-Phase does not rely on any initial welding parameters. Moreover, the amount and size of the Laves-Phase present depend on creep-rupture duration and elevated temperature exposure [17]. Typical size and distribution of the $\mathrm{A}_{2} \mathrm{~B}$-type phases are in the range of $0.1-$ $1 \mu \mathrm{m}$, with a peak in the probability function at $0.25 \pm 0.15 \mu \mathrm{m}$ according to Dimmler et al. [18]. Due to the limits of common LOM (calculated according [19]), with a wavelength $\lambda=380-780 \mathrm{~nm}$, numerical aperture $A=0.85$ (objective and immersion dependent) the following minimal lateral resolution is given:

$d_{\min }=0.61 \cdot \frac{\lambda}{a A}=0.2727 \mu \mathrm{m}$.

This confirms the possibility to determine the Laves-Phase in the LOM in its most common state $>0.25 \mu \mathrm{m}$ after CRT at elevated temperatures. It should be mentioned that this calculated submicrometer resolution usually cannot be reached due to lens defects, chromatic and spherical aberration.

Metallographic sample preparation and lack of suitable etching to reveal suitable phase contrasting limit the utility of LOM characterization results. This study aims to address some of these deficiencies and demonstrates the possibility of visualizing Laves-Phase with specific etching methods and LOM.

The cathodic color tint etching method according to Lichtenegger-Bloech was applied at certain conditions of CB2 weld metals microstructure. To cover a wide spectrum of microstructures the weld metal was investigated in aswelded condition (AW), after PWHT and PWHT followed by CRT. Materials characterization aimed at generating a suitable contrast and imaging via computer-supported software analysis. Results of the metallographic imaging were compared to scanning electron microscopy and energy dispersive x-ray spectroscopy (EDS) analyses as well as already published data. Due to these extensive comparisons it can be said that a valid identification method for Lavesphase in creep-resistant $9 \% \mathrm{Cr}$-steels was found.

\section{Experimental Details}

\section{Materials Data}

Weld metal of 9\% Cr-steel GX13CrMoCoVNbNB9-2-1 (CB2) was chosen for investigation. Welds were performed with a rutile-basic flux cored wire Böhler CB2 Ti-FD (EN ISO 17634-A: T Z CrMo9VNbB P M 1). Samples were welded with a conventional power source on $\mathrm{DC}+$ under mixed gas (M21-Ar $\left.+18-25 \% \quad \mathrm{CO}_{2}\right)$. The typical chemical composition according to the product data sheet of the all-weld metal is given in Table 1 .

After welding, samples were cut according to EN ISO 15614-1. PWHT was performed at $730{ }^{\circ} \mathrm{C}$ for $24 \mathrm{~h}$. Uniaxial creep-rupture tests were performed according to DIN EN 10291 at $625^{\circ} \mathrm{C}$. The samples loaded with $90 \mathrm{MPa}$ fractured after about $13,000 \mathrm{~h}$.

\section{Metallographic Samples Preparation and Etching Methods}

Metallographic samples were taken at AW, PWHT, and CRT conditions. Specimens were embedded in a wood-filled, duroplastic phenol resin (50 $\mathrm{mm}$ diameter). Embedded specimens were prepared with a diamond grinding disk (Mesh 220) at $30 \mathrm{~N}$ force each sample. Afterward, samples were fine grinded with a diamond lapping disk using a $6-\mu \mathrm{m}$ lubricating, polycrystalline diamond suspension. Further, a $1-\mu \mathrm{m}$ polycrystalline diamond suspension at a woven acetate cloth was used. Finishing polishing was performed with an alkalic 0.2- $\mu \mathrm{m}$ fumed silica dispersion (oxide dispersion solution polishing-ODS) using a foamed neoprene polishing cloth. Polishing should not exceed $2 \mathrm{~min}$ at a rotation speed of $100 \mathrm{rpm}$, to avoid many occurring artefacts. After each cycle samples should be properly water cleaned. Scanning electron microscopy investigations were
Table 1 Typical chemical composition of CB2 all-weld metal

\begin{tabular}{llllllllllll}
\hline & $\mathrm{C}$ & $\mathrm{Si}$ & $\mathrm{Mn}$ & $\mathrm{Cr}$ & $\mathrm{Ni}$ & $\mathrm{Mo}$ & $\mathrm{V}$ & $\mathrm{Nb}$ & $\mathrm{Co}$ & $\mathrm{N}$ & $\mathrm{B}$ \\
\hline $\mathrm{CB} 2 \mathrm{FCW}$ & 0.12 & 0.2 & 0.9 & 9.0 & 0.2 & 1.5 & 0.2 & 0.03 & 1.0 & 0.02 & 0.006 \\
\hline
\end{tabular}


performed immediately after ODS; at first after selective etching. The etchant used was Villella's reagent, a mixture of $1 \mathrm{~g}$ picric acid and $5 \mathrm{ml}$ hydrochloric acid in $100 \mathrm{ml}$ ethanolic solution. It should be mentioned that the samples must be washed free of any residue before etching [1].

After scanning electron microscopy analyses, samples were repolished and subsequently etched with the cathodic color tint etchant Lichtenegger-Bloech at room temperature for LOM examination [7]. The etchant used was a mixture of $0.5 \mathrm{~g} \mathrm{~K}_{2} \mathrm{~S}_{2} \mathrm{O}_{5}$ and $20 \mathrm{~g} \mathrm{NH}_{4} \mathrm{HF}_{2}$ in $100 \mathrm{ml}$ aqueous solution. All samples were etched with freshly prepared etchant, directly after polishing for optimal contrasting since used etchants suffer from dilution, interfering remains of previous etching or reduced etching attack. During the carefully controlled etching the specimens were immersed with the polished side up, the etchant was applied, and a gentle nodding of the sample for a homogenous etching deposition was carried out. Effects of chemical reactions appear after a few seconds; etching was stopped at the point of optimal contrasting. Following etching, the samples must be thoroughly cleaned with water and dried.
LOM analyses were performed weld morphology and phase interpretation at different materials conditions. Phase verification and characterization was performed via scanning electron microscopy supported by EDS. Imaging data analysis (ROI particle analysis) on Laves-Phase was performed on CRT sample to verify the existence, the size distributions, and area fractions of such phases. To guarantee a satisfying determination of phases within computer-aided imaging, pictures should be taken at a high image resolution ( $\geq 5 \mathrm{MP}$ ).

\section{Results}

\section{Materials Microstructural Characterization}

Weld microstructures of the tested steel grade CB2 are shown in Fig. 1. Lath martensitic structure was observed as dominant phase within the AW matrix. Carbides, LavesPhase as well as eventually occurring delta-ferrite were not found within the observed areas using LOM and scanning

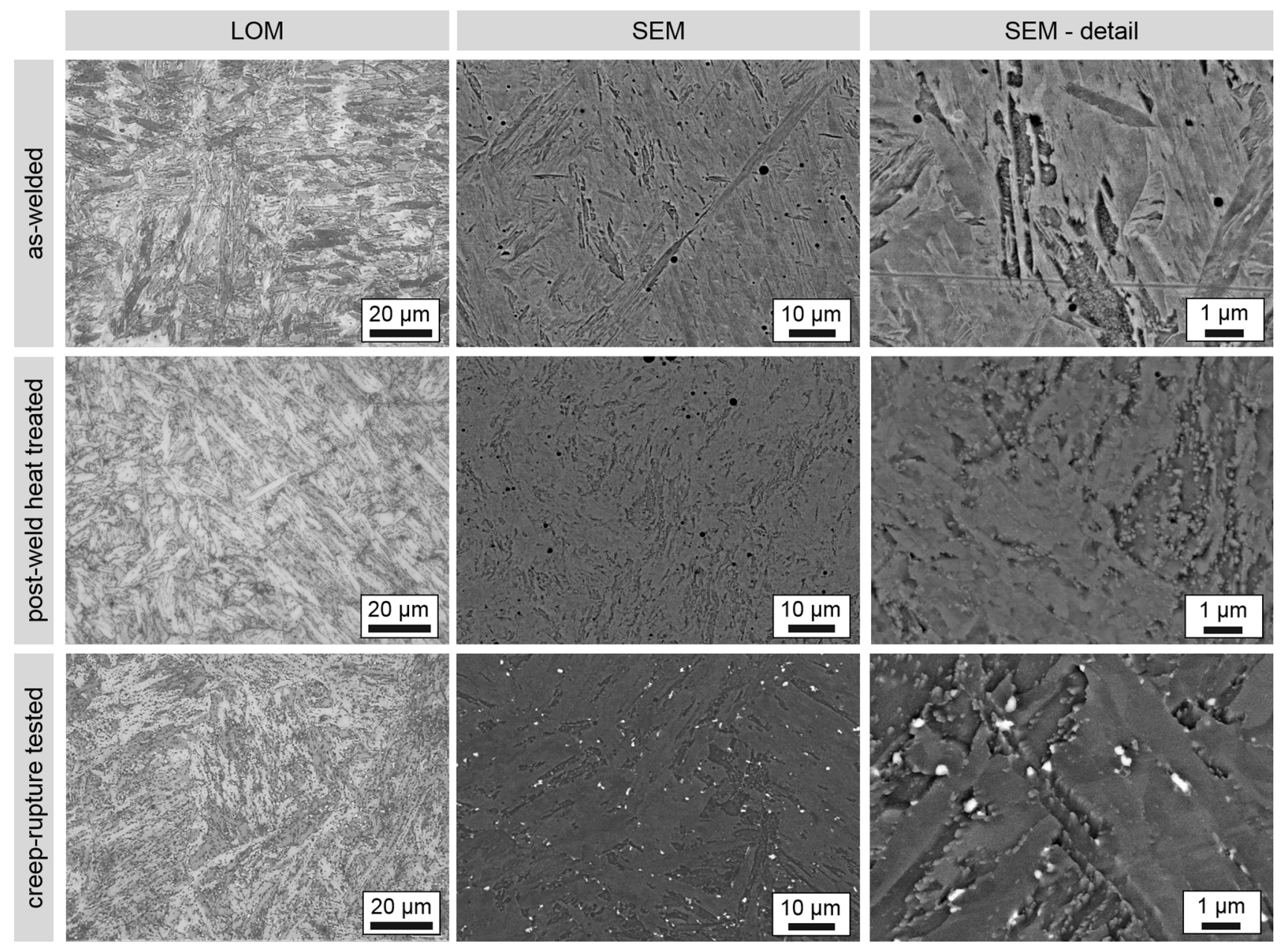

Fig. 1 Microstructural evolution of all materials conditions investigated with light optical and scanning electron microscopy 
electron microscopy. This can be ascribed to the etchants contrasting effect; no inconstancies within the microstructure were observed, which usually suggests the absence of other phases visible in LOM. Rare, blackish, globular areas within the microstructures stems from oxide or slag inclusions typical for welding. The lack of other phases can be confirmed by means of backscatter imaging via scanning electron microscopy. Conceivably, occurring phases which were not visible due to polishing effects should have been displayed by selective etching.

After PWHT the microstructure changes to tempered martensite as shown in Fig. 1. Finely dispersed particle colonies were found with $\mathrm{LOM}$ at $1000 \times$ magnification. This appearance is typical for precipitated, carbon enriched areas, such as agglomerations of carbides. These particles were determined with scanning electron microscopy after
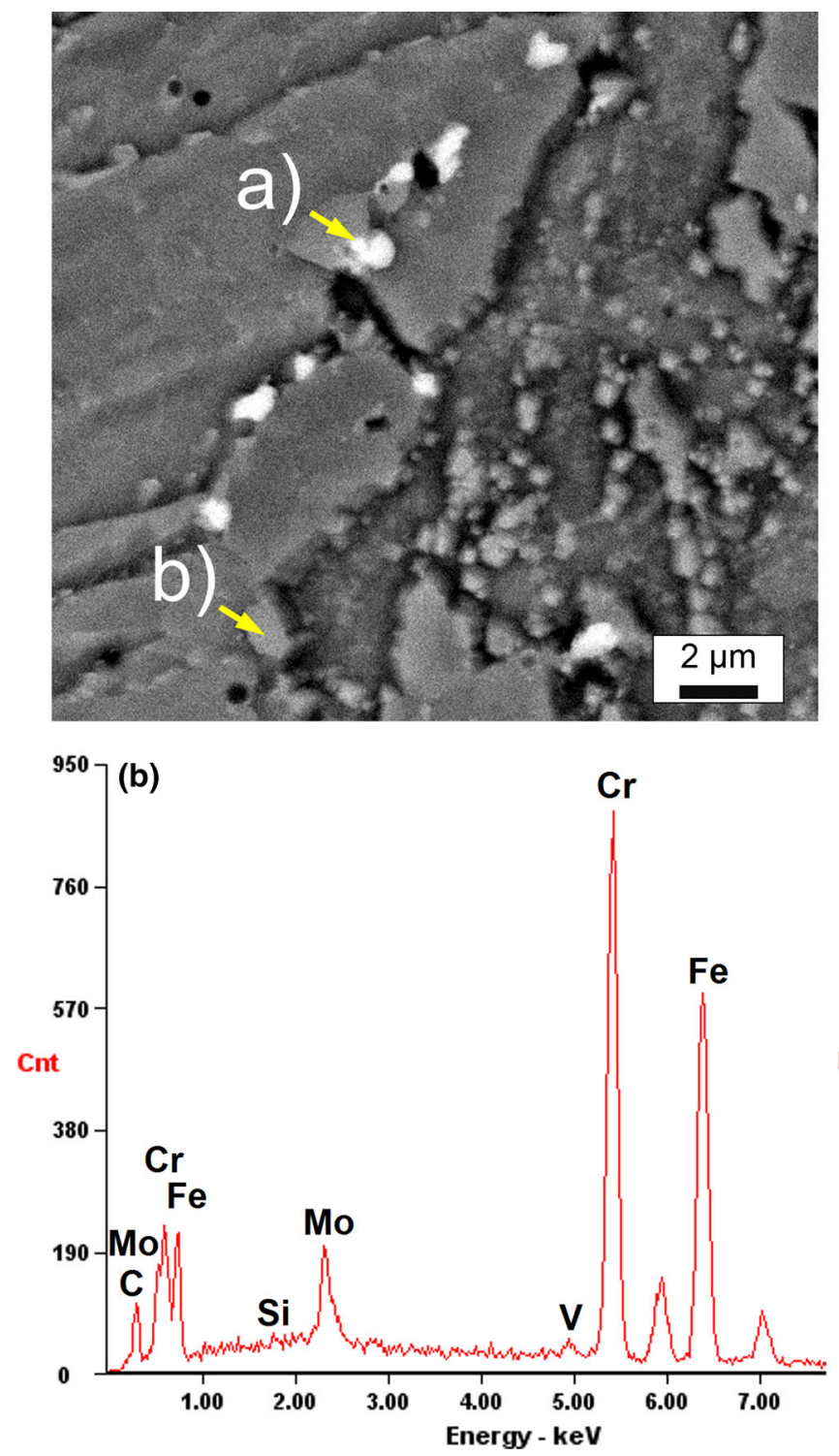

selective etching as well. Using scanning electron microscopy, the particles grayscale is likewise equal to that of the matrix, as shown in Fig. 1. Statistical evaluation of the carbides by means of computer-based software was not possible due to insufficient contrast between particles and matrix.

LOM investigation of the weld metals microstructures after CRT shows strongly dissipated tempered martensite with finely dispersed particles. It can be seen that additional small white particles occur within the matrix in comparison with the previously examined structures. Gray regions within the microstructure represent carbon richer areas, which indicate carbide agglomerates.

The typical chemical compositions of the particles and the matrix were analyzed using EDS. Figure 2 represents selectively etched samples observed by means of scanning
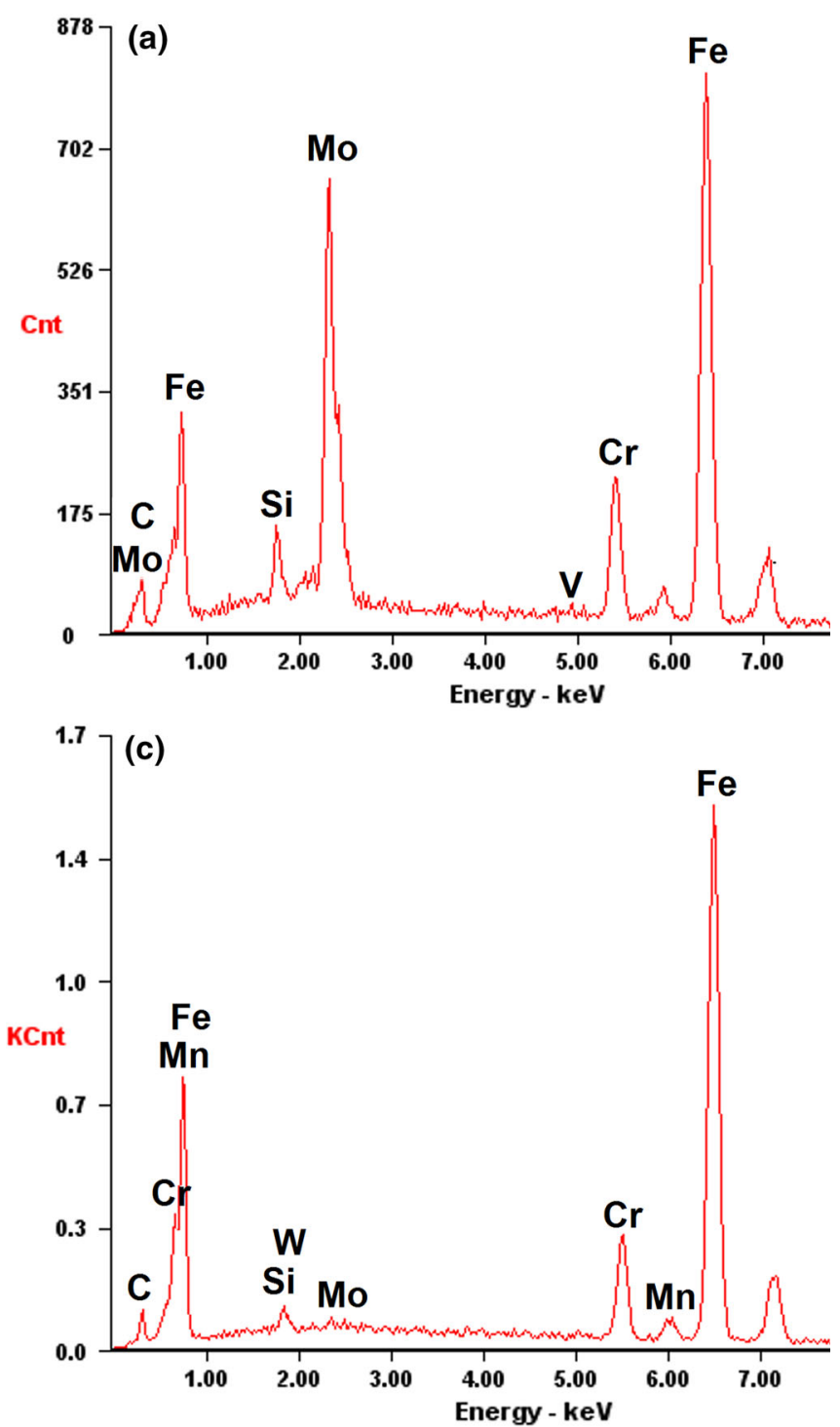

Fig. 2 EDX analyses of different precipitations: (a) Laves-Phase, (b) carbide, (c) matrix 
electron microscopy (backscatter mode). For the phase identification, EDS analyses were performed as given in the figure. White highlighted particles were found in the weld metals microstructure caused by varying density owing to different chemical compositions. EDS analyses points out that $\mathrm{Si}$ can be found in these white phases (Fig. 2(a)). Carbon was not detected, which was measured over all white particles within the ROI of the structures, which indicates the presence of Laves-Phase in microstructures after CRT. The gray particles (Fig. 2(b)) are highly enriched in $\mathrm{Cr}$; Mo was also found. The detected chemical formula of the particles is $\mathrm{Cr}(\mathrm{Mo})_{x} \mathrm{C}_{y}$, indicating the presence of carbides dispersed throughout the matrix. For a comparison of the particles to the matrix the EDS spectra of the matrix are given in Fig. 2(c). A spectra close to the nominative chemical composition can be pointed out. At this stage a difference in the original and the measured chemical compositions shall be mentioned caused by the energy dissipation of the electron beam larger than the actual particle size.

\section{Microstructural Evaluation Using LOM}

For the comparison of scanning electron microscopy and LOM, a comparison is given in Fig. 3, where Fig. 3(a) represents a color tint etched sample section using LOM and Fig. 3(b) the matching area via scanning electron microscopy analysis after selective etching. Micrographs were taken close to the fractured surface of the CRT sample, which explains the comparatively high amount of creep porosity. As seen in the figures, the proposed etching method represents an equal appearance of Laves-Phase. A direct correlation of LOM and scanning electron microscopy can be pointed out, indicating that the proposed etching method is a simple and reliable way to determine present Laves-Phase via LOM.

The influence of the etching time is presented in Figs. 3 and 4. Contrasting after a short etching time is given in Fig. 3(a), intermediate etching time in Fig. 4(a), and long etching time in Fig. 4(b). As seen in the figures, a sufficient contrasting of the Laves-Phase can be achieved at increased etching times.
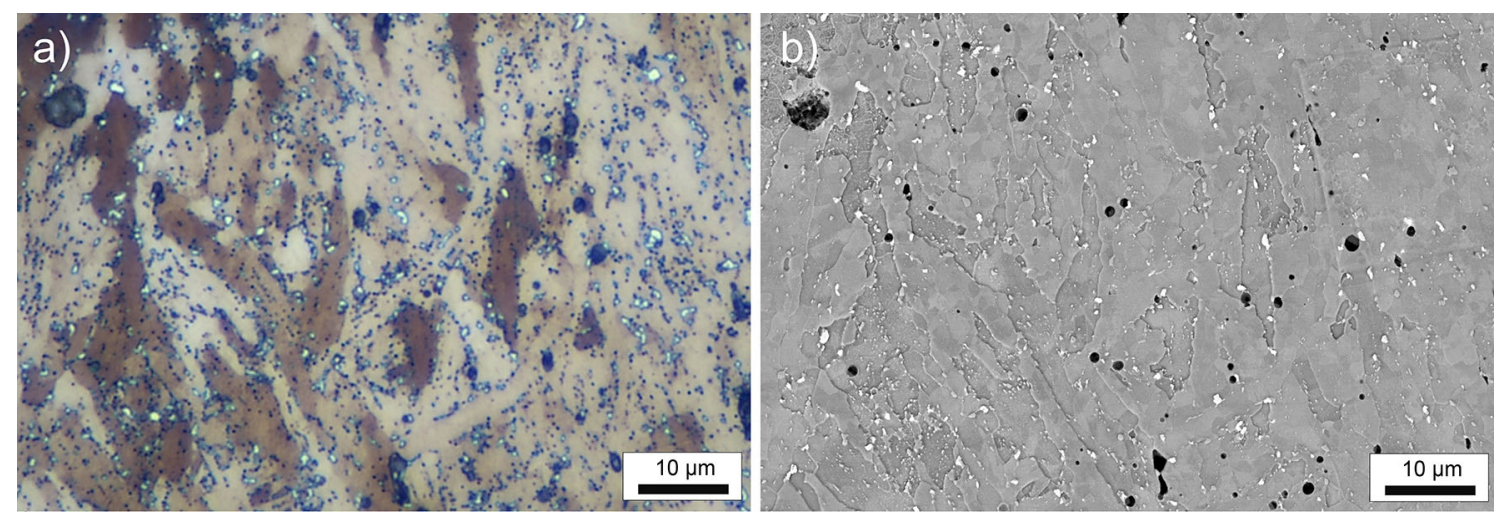

Fig. 3 Microstructural evolution: (a) after color tint etching and light optical analysis, (b) selectively etched with scanning electron microscopy
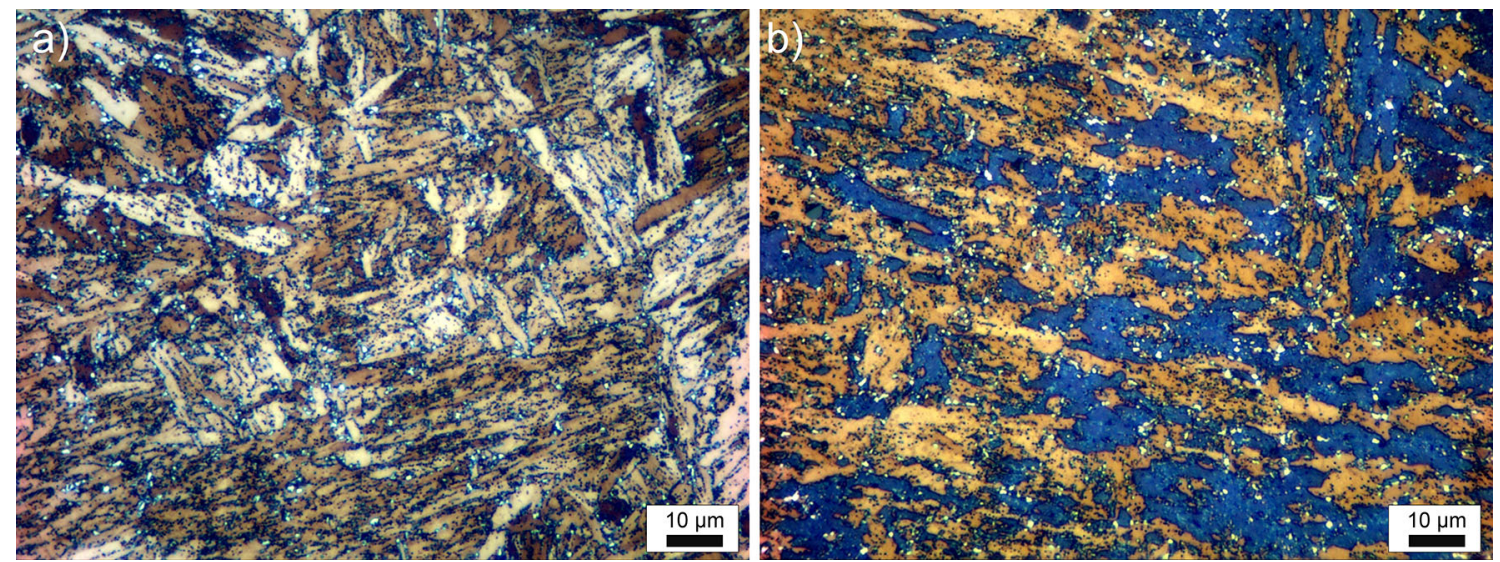

Fig. 4 Microstructure after color tint etching of creep-rupture tested samples: (a) intermediate etching time, (b) long etching time 
At longer times a deeper brownish/blueish color of the martensitic matrix is developed, which represent different alloying contents and grain orientations. Due to the brighter appearance of the Laves-Phase a better contrast for more precise ROI particle analyses can be pointed out.

\section{Microstructural Imaging and Laves-Phase Size Distribution}

Weld metal microstructure images of CRT sample were taken for detailed one-phase ROI particle analysis. Pictures from LOM (color tint etched) were compared to those collected using scanning electron microscopy. The distribution and size (area fraction and circle evaluated diameter) of the white occurring Laves-Phase were measured and likened.

Results of the ROI particle analyses are shown in Fig. 5. The figure represents the size distribution of the appearing Laves-Phase in (a) LOM and (b) scanning electron microscopy. As seen in the figure, both utilized methods show similar size distributions. The differences stem from the more accurate particle analysis after scanning electron microscopy due to sharper edges within the microstructural images, which causes the decrease in the relative frequency from 0.175 to $0.325 \mu \mathrm{m}$. In both cases the amount $<0.125 \mu \mathrm{m}$ is too high, caused by tiny particles, which were detected from the software. Usual deviation of the values given was $\sim 10 \%$.

The average values (weighted mean from the ROI particle analysis) for circle evaluated diameter are $0.44 \mu \mathrm{m}$ for scanning electron microscopy and $0.50 \mu \mathrm{m}$ for LOM. Area fractions are $1.03 \pm 0.07 \mu \mathrm{m}$ for scanning electron microscopy and $1.10 \pm 0.14 \mu \mathrm{m}$ for LOM, which is in the usual range for weld metals. The measured area fraction for both means of microscopy is comparable to previous literature [31]. Due to the similarity of both microscopic methods, an additional proof for the validity of the proposed Laves-Phase identification is given. The literature reconciliation proves the evidence of the Laves-Phase

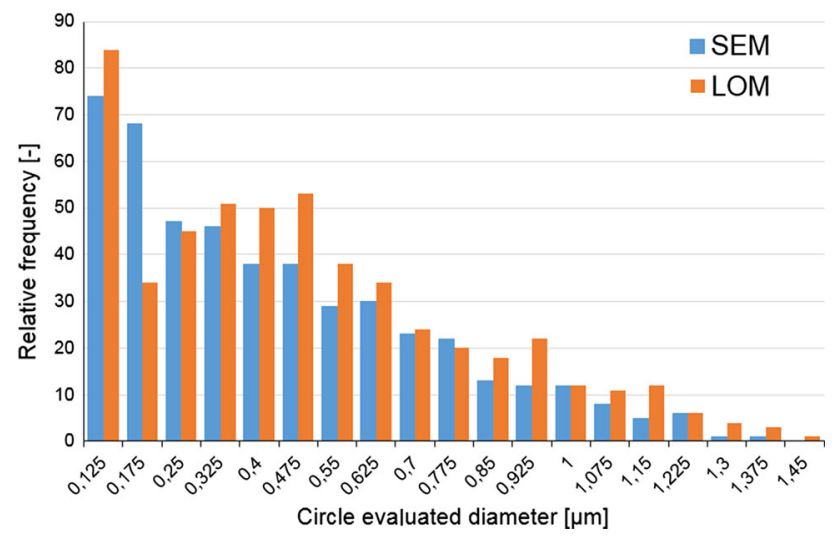

Fig. 5 Circle evaluated diameter plot of both utilized microscopic methods caused by the comparability of area fraction and circle evaluated diameter [27, 29-31].

\section{Discussion}

\section{Influence of Thermal and Mechanical History on the Weld Morphology}

Due to their alloying concept $9 \%$ Cr-steels have a fully lath martensitic structure, decorated with carbide precipitations during PWHT. The formation of carbides on grain and subgrain boundaries alongside the alloying elements is the key factor for the creep-resistance of such steel grades [20]. Long-time exposure at elevated temperature and additional mechanical loads lead to the thermodynamically stable Laves-Phase which tend to coarsen via Ostwaldripening [21]. Therefore, none of the mentioned precipitated phases can be identified in AW condition.

Silicon only was found in the Laves-Phase via EDS analysis. This is caused by the total solubility of $\mathrm{Si}$ in $\mathrm{Fe}$ and related intermetallic phases. In carbides $\mathrm{Si}$ was not detected, which origins in the fact that $\mathrm{Si}$ is not able to form carbides as a consequence of thermodynamic stability $[22,23]$. Based on these facts, the proof of the Laves-Phase by means of scanning electron microscopy-EDS can be set. A comparison of the same ROI within both microscopic methods and EDS analysis establishes the capability to identify the Laves-Phase with specific etching techniques.

\section{Laves-Phase Determination}

Laves-Phase identification can be performed by contrasting with cathodic color tint etching. Anodic areas with significantly lower, respectively, no carbon content compared to the matrix remained white. This origins from differences in their electrochemical potential $[7,24,25]$. The longer the etching time, the clearer the difference between LavesPhase and matrix; at shorter times the difference between carbide structures and matrix is more pronounced.

Brown and blue color variations in the martensitic matrix originate from deviations in the grain orientations. Heterogeneous morphologies create different dense etching layers resulting in the variation of the appearance of the martensite in the LOM [26]. The distinct orientations show various color scales and etching pits, which can also be seen in scanning electron microscopy investigations. Further, it should be mentioned that without previous etching the differentiation of carbides from matrix is tough in scanning electron microscopy, while the Laves-Phase can be detected comparatively easy by use of backscatter mode. This originates from the higher mean atomic number 
of the Laves-Phase $(\mathrm{Fe}, \mathrm{Cr})_{2} \mathrm{Mo}$ compared to carbides $\mathrm{M}_{x} \mathrm{C}_{y}$ [27].

It can be said that the Lichtenegger-Bloech etchant enables a suitable contrasting for materials characterization by means of LOM. The gained images can be easily analyzed by ROI particle size analyses. The Laves-Phase size investigated is around $400 \mathrm{~nm}$ in a certain average and fits well to published data measured [13, 18, 28, 29] and simulated $[30,31]$ in previous literature for CRT at comparable stress levels. Also, the mean area fraction of present Laves-Phases which saturates at $1 \%$ compares well between our study and previous literature [31], confirming the presence of such phases with the simple determination via the mentioned metallographic route.

With the utilized procedure, a route to characterize Laves-Phase in LOM was presented. Nevertheless, the need of an adequate metallographic preparation and a proper etching technique cannot be neglected. A thorough knowledge on the influence of cutting, samples preparation, grinding, and polishing is crucial to get optimal imaging and enables perfect metallographic imaging [7, 8, 21]. Certain parameter like the correct pressure during grinding and polishing should not exceed $30 \mathrm{~N} /$ sample; otherwise, diamonds may be worked into the surface. For etching, certain knowledge is needed, since even fresh etchants lead to different etching times, depending on the surface state of the specimen. Grinding at more mesh-sizes does not affect the outcome of the finishing polishing.

Since weld metals suffer from segregation and oxide inclusions, the materials characterization via metallography is comparatively tough [32]; nevertheless, with adequate parameter and procedures, even small phases like the Laves-Phase can be contrasted and visualized. Furthermore, a thorough understanding of weld microstructures is necessary to comprehend the effect of etchants for analyzing and describing their morphology.

\section{Conclusions}

Based on the study within this work, the following conclusions were drawn:

- Color tint etching according Lichtenegger-Bloech is a satisfying way to identify phases in $9 \% \mathrm{Cr}$-steel using light optical microscopy. All phases are cathodically layered and contrasted, except the Laves-Phase remains white, which enables a simple determination of the presence of this phase.

- Creep-resistant 9\% Cr-steels show fully lath martensitic microstructure in as-welded condition. After post-weld heat treatment a tempered martensitic structure can be observed. After post-weld heat treatment and creep- rupture testing at elevated temperatures also the $(\mathrm{Fe}, \mathrm{Cr})_{2}(\mathrm{Mo})$-Laves-Phase can be found on grain boundaries in the weld microstructure.

- The benefits of this used etching routine are the comparatively large analyzed area and no need for advanced examination methods such as scanning electron microscopy.

- Present phases were found at all examination techniques. Carbides were only found in clusters within light microscopy due to their size below the resolving potential. The presence of Laves-Phase and carbides was confirmed by scanning electron microscopy, energy dispersive $\mathrm{x}$-ray spectroscopy and particle size, distribution and area fraction analysis.

Acknowledgments This work was funded by the "Austrian CometProgram" (governmental funding program for pre-competitive research) via the Austrian Research Promotion Agency (FFG) and the TecNet Capital GmbH (Province of Lower Austria) and has been carried out within the "Austrian Center of Competence for Tribology” (AC2T research GmbH).

\section{References}

1. G.F. Van der Voort, ASM Handbook Volume 9-Metallography and Microstructures; Color Metallography (ASM International, Materials Park, 2004)

2. G.F. Vander Voort, Metallography of Welds. Adv. Mater. Process. 169, 19-23 (2011)

3. A. Kipelova, A. Belyakov, R. Kaibyshev, Laves Phase Evolution in a Modified P911 Heat Resistant Steel During Creep at $923 \mathrm{~K}$. Mater. Sci. Eng. A 532, 71-77 (2012)

4. H. Cui, F. Sun, K. Chen, L. Zhang, R. Wan, A. Shan, J. Wu, Precipitation Behavior of Laves Phase in $10 \% \mathrm{Cr}$ Steel X12CrMoWVNbN10-1-1 During Short-Term Creep Exposure. Mater. Sci. Eng. A 527, 7505-7509 (2010)

5. I. Fedorova, A. Belyakov, B. Kozlov, V. Skorobogatykh, I. Shenkova, R. Kaibyshev, Laves-Phase Precipitates in a LowCarbon 9\% Cr Martensitic Steel During Aging and Creep at 923 K. Mater. Sci. Eng. A 615, 153-163 (2014)

6. H. Rojacz, G. Mozdzen, F. Weigel, M. Varga, Microstructural Changes and Strain Hardening Effects in Abrasive Contacts at Different Relative Velocities and Temperatures. Mater. Charact. 118, 370-381 (2016)

7. G. Petzow, Metallographisches, Keramographisches, Plastographisches Ätzen (Gebrüder Borntraeger, Berlin, 2014)

8. B.L. Bramfitt, A.O. Benscoter, Metallographer's Guide-Practices and Procedures for Iron and Steel (ASM International, Materials Park, 2001)

9. J. Angeli, E. Füreder, M. Panholzer, A. Kneißl, Ätztechniken für die Phasencharakterisierung von niedriglegierten Dual-Phasenund TRIP-Stählen. Prakt. Metallogr. 43, 489-504 (2006)

10. W. Liu, X. Liu, F. Lu, X. Tang, H. Cui, Y. Gao, Creep Behavior and Microstructure Evaluation of Welded Joint in Dissimilar Modified 9Cr-1Mo Steels. Mater. Sci. Eng. A 644, 337-346 (2015)

11. M. Isik, A. Kostka, G. Eggeler, On the Nucleation of Laves Phase Particles During High-Temperature Exposure and Creep of Tempered Martensite Ferritic Steels. Acta Mater. 81, 230-240 (2014) 
12. H. Rojacz, H. Pahr, S. Baumgartner, K. Adam, M. Varga, Welding Parameters and Their Influence on the Abrasion Resistance of Structural Steels at Elevated Temperatures. Key Eng. Mater. 721, 461-466 (2016)

13. S. Baumgartner, H. Pahr, R. Schnitzer, Creep Rupture Strength of Dissimilar CB2-P92 FCW Joint Welds, Proc. 8th Conf. Adv. Mater. Technol. Fossil Power Plant, Pine Cliffs Algarve, 2016

14. J. Kasl, D. Jandova, Metallography of CB2 Steel Used for Cast Turbine Components. Mater. Sci. Forum 782, 179-185 (2014)

15. R. Bürgel, Handuch Hochtemperatur-Werkstofftechnik (Vieweg\&Sohn Verlag, Wiesbaden, 2006)

16. G. Dimmler, "Quantifizierung der Kriech- und Zeitstandfestigkeit von 9-12\% Cr-Stählen auf Mikrostruktureller Basis," Ph.D. thesis, Graz University of Technology, Austria, 2003

17. Z. Xia, C.Y. Wand, C. Lei, Y.-T. Lai, Y.-F. Zhao, L. Zhang, Growth Kinetics of Laves Phase and Its Effect on Creep Rupture Behavior in 9Cr Heat Resistant Steel. J. Iron Steel Res. Int. 23, 685-691 (2016)

18. G. Dimmler, P. Weinert, E. Kozeschnik, H. Cerjak, Quantification of the Laves Phase in Advanced 9-12\% Cr Steels Using a Standard SEM. Mater. Charact. 51, 341-352 (2003)

19. H.A. Stuart, G. Klages, Kurzes Lehrbuch der Physik (Springer, Berlin, 2010)

20. F. Abe, Precipitate Design for Creep Strengthening of $9 \% \mathrm{Cr}$ Tempered Martensitic Steel for Ultra-Supercritical Power Plants. Sci. Technol. Adv. Mater. 9, 013002 (2008)

21. G.F. Vander Voort, Metallography_Principles and Practice (ASM International, Materials Park, 1984)

22. S.C. Chueh, "Computer Calculations of Metastable and Stable Fe-C-Si Phase Diagrams from Binary Thermodynamic Properties," Ph.D. thesis, Iowa State University, Aimes, 1986
23. ASM Handbook Committee, ASM Handbook Vol. 3: Alloy Phase Diagrams (ASM International, Materials Park, 1992)

24. J. Angeli, "Metallkundliche Charakterisierung von niedriglegierten, höchstfesten Dual-Phasen- und TRIP-Stählen," Ph.D. thesis, Montanuniversität Leoben, Leoben, 2004

25. E. Weck, E. Leistner, Fachbuchreihe Schweißtechnik 77: Metallographische Anleitung zum Farbaetzen nach dem Tauchverfahren. Teil II: Farbaetzmittel nach Beraha und ihre Abwandlungen (DVS-Verlag, Düsseldorf, 1983)

26. P. Haslberger, W. Ernst, R. Schnitzer, Mikrostrukturielle Charakterisierung von ultrahochfesten Schweißgütern. Berg und Hüttenmännische Monatshefte 161, 321-324 (2016)

27. K. Chalk, "Weld consumables and PWHT for P92 power plant steel," Ph.D. thesis, University of Nottingham, Nottingham, 2013

28. M. Durand-Charre, Microstructure of Steels and Cast Irons (Springer, Berlin, 2003)

29. L. Korcackova, J. Hald, A.J. Somers, Quantification of Laves Phase Particle Size in 9CrW Steel. Mater. Charact. 47, 111-117 (2011)

30. M. Schuler, S. Baumgartner, R. Schnitzer, N. Enzinger, Effect of Tempering Time on the Mechanical Properties of P91 Flux Cored Wire Weld Metal. Weld. Weld World 98, 903-913 (2014)

31. C. Schlacher, "Kriechschädigungsuntersuchungen von Schweißverbindungen eines neu entwickelten Chromstahls," Ph.D. thesis, TU Graz, Graz, 2005

32. B. Taylor, A. Guisnier, Struers Application Notes-Metallography of Welds (Struers, Ballerup, 2016) 